\title{
MAPEAMENTO DE PROCESSOS EM BIBLIOTECAS: REVISÃO DE LITERATURA E APRESENTAÇÃO DE METODOLOGIAS'
}

\author{
PROCESS MAPPING IN LIBRARIES: LITERATURE REVIEW AND PRESENTATION OF \\ METHODOLOGIES
}

\author{
Marciléia Aparecida de Paula ${ }^{2}$ \\ Valéria Martin Valls ${ }^{3}$
}

RESUMO: Considerando a importância de se implantar a Gestão da Qualidade nas instituições, busca revisar a literatura sobre os temas Gestão da Qualidade, Gestão por Processos e Mapeamento de Processos, relacionando-os com o ambiente bibliotecário. Além disso, apresenta metodologias encontradas na literatura que já foram utilizadas para o Mapeamento de Processos em bibliotecas (Modelagem de Processos de Negócios (MPN), ARIS/EPC, Formulário SIPOC, Servpro e Roteiro do Inpe).

PALAVRAS-CHAVE: Gestão da qualidade. Gestão por processos. Mapeamento de processos. Biblioteca.

ABSTRACT: Considering the importance of implementing the Quality Management in institutions, aims to review the literature about the topics Quality Management, Process Management and Process Mapping, relating them to the librarian environment. Moreover, it presents methodologies found in the literature that have been used for Process Mapping in libraries (Business Process Modeling (BPM), ARIS / EPC, Form SIPOC, Servpro and Screenplay INPE).

KEYWORDS: Quality management. Process management. Process Mapping. Library.

\footnotetext{
${ }^{1}$ Artigo baseado no Trabalho de Conclusão de Curso apresentado à Escola Pós-Graduada em Ciências Sociais da Fundação Escola de Sociologia e Política de São Paulo como requisito para a obtenção do título de Especialista em Gerenciamento de Sistemas e Serviços de Informação.

${ }^{2}$ Marciléia Aparecida de Paula: Especialista em Gerência de Sistemas e Serviços de Informação pela Fundação Escola de Sociologia e Política de São Paulo (FESPSP). Bibliotecária na Universidade Federal do ABC (UFABC). Email: marcidepaula@yahoo.com.br

${ }^{3}$ Doutorado em Ciências da Comunicação (2005), Mestrado em Ciências da Comunicação (1998) e Graduação em Biblioteconomia e Documentação (1990) pela Escola de Comunicações e Artes da Universidade de São Paulo - ECA/USP, além de extensão universitária em Docência pela Fundação Getúlio Vargas - FGV (2008). Coordenadora e docente do curso de graduação em Biblioteconomia e Ciência da Informação da Fundação Escola de Sociologia e Política de São Paulo (FaBCl/FESPSP) e Coordenadora de curso e docente de pósgraduação da Escola Pós-Graduada da FESPSP (Núcleo de Ciência da Informação). Docente do MBA em Gestão Empresarial e Coaching (parceria FESPSP e SLAC). Email: valls@fespsp.org.br Submetido em: 29/10/2013 - Aceito em: 03/07/2014.
} 


\section{INTRODUÇÃ̃o}

Ao longo da história as bibliotecas passaram por grandes transformações. De meros depósitos de livros, atualmente possuem a importante função de disponibilizar produtos e serviços que possibilitem o acesso a informações fidedignas e de qualidade por parte dos usuários que a elas se dirigem. Nesse contexto, é de suma importância a preocupação com o nível de qualidade dos serviços oferecidos, a fim de que os mesmos estejam voltados a atender as necessidades dos usuários. Dessa forma, eles ficarão satisfeitos e a qualidade percebida por eles fará com que passem a ter uma imagem positiva com relação à instituição que lhes prestou o serviço.

Para tanto, surge a preocupação, por parte dos dirigentes de tais instituições, de se atualizar as práticas gerenciais utilizadas. Tal preocupação faz com que os profissionais bibliotecários deixem de ter apenas conhecimentos técnicos sobre a área da Biblioteconomia, e voltem-se à área da Gestão, mais especificamente à Gestão da Qualidade, pois, "[...] a qualidade, como nova filosofia gerencial, tenta atenuar a diferença entre o que a organização oferece e o que seu usuário espera dela" (ABREU; ANDALIA, 1998, p. 80, tradução nossa).

No entanto, para que a Gestão da Qualidade seja colocada em prática em uma instituição deve-se conhecer, com profundidade, os processos de trabalho desenvolvidos. Isso pode ser alcançado através da atividade de Mapeamento de Processos, que surge a partir do estabelecimento da forma de administração denominada Gestão por Processos que é "[...] uma metodologia empregada para definir, analisar e gerenciar as melhorias no desempenho dos processos da empresa, com a finalidade de atingir as condições ótimas para o cliente" (RADOS et al., 1999, p. 4 apud REIS; BLATTMANN, 2004, p. 10). Ou seja, a Gestão por Processos visa a aumentar a qualidade dos serviços oferecidos aos usuários, sendo, assim, um dos princípios da Gestão da Qualidade que pode, além de ser empregado em empresas, ser utilizado em bibliotecas também.

Dessa forma, como as práticas gerenciais mencionadas visam trazer melhorias para os processos colocados em prática numa instituição, busca-se apresentar uma revisão de literatura sobre os temas Gestão da Qualidade, Gestão por Processos e Mapeamento de Processos, relacionando-os com o ambiente bibliotecário, bem como expor modelos encontrados na literatura e que já foram utilizados para o Mapeamento de Processos em bibliotecas. Por fim, serão expostas algumas considerações acerca do que foi apresentado. 


\section{GESTÃO DA QUALIDADE}

Com a globalização e o rápido avanço da sociedade, o mundo vem se tornando cada vez mais competitivo. Para sobreviver a essa dinâmica as instituições, sejam com ou sem fins lucrativos, precisam estabelecer estratégias que as ajudem a permanecer competitivas no mercado com relação a seus concorrentes. Esse contexto fez com que as empresas passassem a se preocupar com a qualidade dos produtos e serviços oferecidos aos seus clientes. $\mathrm{O}$ aumento da preocupação com os direitos dos consumidores (que fez com que os mesmos passassem a ter uma maior conscientização com relação a seus direitos) também auxiliou para que as empresas direcionassem seus olhares para a qualidade passando, inclusive, a considerar a opinião dos mesmos. Isso propiciou uma mudança na relação entre fornecedores e consumidores. Caso contrário, os primeiros estariam fadados a perder mercado e clientela.

Para se adaptar a essa nova dinâmica, algumas empresas tiveram que passar por mudanças estratégicas, pois, "a competição é tão intensa e os mercados tão dinâmicos e voláteis que a necessidade de evolução tem se tornado a força dominante na estratégia das empresas" (RUHLI, 1997 apud MARCO, 1999, p. 2, grifo nosso). A necessidade de evolução destacada diz respeito, dentre outras coisas, à disposição para adotar novos procedimentos de trabalho que visem atender às novas estratégias estabelecidas pela empresa.

Nesse sentido, se a mudança estratégica da empresa estiver relacionada à qualidade, se faz necessário conhecer novas possibilidades para a implementação da mesma. Dentre tais possibilidades destaca-se a Gestão da Qualidade que pode ser entendida:

[...] como a forma de gestão de uma organização, definida pela alta direção, tendo como base as necessidades dos seus clientes, baseada na identificação de requisitos de qualidade do produto ou serviço, no estabelecimento de um planejamento para que esse padrão seja atingido e na constante busca pela melhoria, em todos os seus aspectos, visando à satisfação dos clientes e a eficácia da organização (VALLS, 2004, p. 173).

Como é possível perceber, o conceito de qualidade aqui é empregado como atendimento das necessidades e exigências dos clientes e consequente satisfação dos mesmos, e não como o simples ato de fazer bem feito. Até porque, fazer bem feito é o mínimo que qualquer empresa deve realizar. O difícil é fazer bem feito atendendo ao que o cliente espera. É exatamente isso que as empresas que aplicam a Gestão da Qualidade em seus processos almejam. 
Para tanto, é preciso que todas as partes da instituição estejam voltadas para o mesmo objetivo estratégico e, assim, é importante a implantação de um Sistema de Gestão da Qualidade (SGQ). Através desse SGQ será estabelecido o conjunto de regras mínimas para que cada setor execute suas tarefas em harmonia com os demais. Para que essas regras mínimas possam ser estabelecidas, a alta direção pode se valer dos oito princípios da Gestão da Qualidade que são apresentados pela NBR ISO 9000 (ASSOCIAÇÃO BRASILEIRA DE NORMAS TÉCNICAS, 2000, p. 2) e estão resumidos abaixo:

1 - Foco no cliente: atender às necessidades do cliente buscando exceder suas expectativas;

2 - Liderança: envolver as pessoas que participam do processo no propósito de atingir os objetivos da organização;

3 - Envolvimento de pessoas: utilizar as habilidades das pessoas para o benefício da organização;

4 - Abordagem de processo: gerenciar as atividades e recursos relacionados como um processo;

5 - Abordagem sistêmica para a gestão: identificar, entender e gerenciar os processos inter-relacionados como um sistema;

6 - Melhoria contínua: ter a melhoria contínua do desempenho da organização como um objetivo permanente;

7 - Abordagem factual para a tomada de decisão: analisar dados e informações para a tomada de decisão;

8 - Benefícios mútuos nas relações com os fornecedores: uma organização e seus fornecedores são interdependentes e uma relação de benefícios mútuos aumenta a capacidade de ambos agregarem valor.

Como é possível perceber através dos oito princípios da Gestão da Qualidade, ela é uma forma de administração que não abrange apenas o resultado em si, ou seja, o produto ou serviço final oferecido. Ela vai além, uma vez que, considera todo o processo existente para o oferecimento do resultado final, bem como os agentes envolvidos e a maximização dos bons resultados. Assim, a Gestão da Qualidade baseia-se numa visão integrada dos processos e recursos (humanos e materiais) disponíveis na instituição na qual está inserida. Seria possível se aprofundar em qualquer um dos oito princípios apresentados. No entanto, isso será feito com o princípio "Abordagem de processo", por estar mais diretamente relacionado com a atividade de Mapeamento de Processos. 


\subsection{Gestão por processos}

Como colocado acima, o princípio da Gestão da Qualidade denominado “Abordagem de processo" visa gerenciar as atividades e recursos relacionados como um processo. "Um processo é uma coleção de atividades que se inicia em uma ou mais entradas e produz uma saída que tem valor para o cliente" (HAMMER; CHAMPY, 1993, p. 35, tradução nossa). Nesse fluxo, existe uma seqüência de atividades onde há uma entrada (input), que pode ser tangível (material) ou intangível (informação). Através dos recursos existentes e guias e regras seguidas pela instituição, essa entrada é processada e sofre uma agregação de valor, dando origem a algum produto ou serviço que constitui a saída (output).

Dessa forma, as atividades são integradas e dependentes umas das outras, ou seja, o trabalho a ser desenvolvido em um setor específico depende, para prosseguir, do resultado do setor anterior. Assim, surge a necessidade de que as instituições abandonem a administração tradicional baseada na estrutura vertical (onde as atividades são gerenciadas por função, tendo seus departamentos e setores administrados de forma isolada) e passem a considerar a estrutura horizontal (que não leva em consideração as divisões departamentais, mas sim a realização dos processos de forma linear, acompanhando todo o seu desenvolvimento, do início até o final). De maneira geral, os processos empresariais são classificados em 3 tipos: de negócio (ou de cliente); organizacionais e gerenciais. Os processos de negócio estão ligados à atuação da empresa e, dessa forma, dão origem aos produtos ou serviços propriamente recebidos pelos clientes. Os processos organizacionais dão apoio aos processos produtivos cuidando, por exemplo, do suprimento de materiais. Os processos gerenciais, por sua vez, incluem as ações e decisões que os gerentes devem tomar para dar suporte aos processos de negócios (GONÇALVES, 2000).

As instituições possuem os 3 tipos de processos apresentados e, a Gestão por Processos vem a ser implementada nesse contexto exatamente para que os processos sejam executados com eficiência, pois, ela "[...] trata-se de uma metodologia empregada para definir, analisar e gerenciar as melhorias no desempenho dos processos da empresa, com a finalidade de atingir as condições ótimas para o cliente" (RADOS et al., 1999, p. 4 apud REIS; BLATTMANN, 2004, p. 10). Dessa forma, a Gestão por Processos realmente vem para corroborar a Gestão da Qualidade, pois, de acordo com a definição colocada, também se preocupa com todo o processo envolvido no oferecimento do resultado final, de maneira que o cliente satisfaça suas necessidades e, também, crie uma imagem positiva com relação à 
instituição, pois, um processo bem desenvolvido será responsável pela criação de valor percebida pelo cliente.

Com o que foi apresentado pode-se dizer que, com a implementação da Gestão por Processos se alcança resultados positivos, dentre eles: visão sistêmica e horizontal dos processos; otimização na utilização dos recursos; melhoria na comunicação entre os departamentos envolvidos no processo; processos e atividades claramente definidos; identificação de mudanças a serem feitas; atendimento das necessidades dos clientes que, como já ficou claro, é o objetivo principal da Gestão da Qualidade e da Gestão por Processos.

No entanto, para que tais vantagens sejam efetivamente alcançadas, é de suma importância que as instituições conheçam, com profundidade, cada um de seus processos. Para tanto, existe a atividade de Mapeamento de Processos que, como será demonstrado a seguir, dará subsídios para que as instituições consigam identificar quais são as atividades desenvolvidas em cada um dos processos, diagnosticando possíveis deficiências, bem como os responsáveis envolvidos.

\subsection{Mapeamento de processos}

Como dito acima, o Mapeamento de Processos é uma das atividades importantes para a implementação da Gestão por Processos, pois, numa organização esta atividade proporciona “[...] o conhecimento e a análise dos processos e seu relacionamento com os dados, estruturados em uma visão top down, até o nível que permita sua perfeita compreensão e obtenção satisfatória dos produtos e serviços, objetivos e resultados dos processos" (MARANHÃO; MACIEIRA, 2004, p. 53).

Assim, o Mapeamento de Processos permite que a instituição analise os fluxos de trabalho partindo dos processos mais abrangentes em direção aos menos abrangentes. Dessa forma, são identificados os macroprocessos, os subprocessos e as atividades envolvidas em todo o fluxo. De acordo com Reis e Blattmann (2004, p. 8) esta é a hierarquia do processo, ou seja,

[...] é a forma de classificar os processos de acordo com o seu grau de abrangência na organização. Sintetiza-se desta maneira: a) Macroprocesso: é um processo que geralmente envolve mais de uma função da organização, cuja operação tem impactos significativos nas demais funções. Dependendo da complexidade, o processo é dividido em subprocessos; b) Subprocessos: divisões do macroprocesso com objetivos específicos, organizadas seguindo linhas funcionais. Os subprocessos recebem entradas e geram suas saídas em um único departamento; c) Atividades: os subprocessos podem ser divididos 
nas diversas atividades que os compõem, e em um nível mais detalhado de tarefas.

De acordo com a citação, o Mapeamento de Processos pode ir do nível dos macroprocessos até o nível das tarefas. Para que essa hierarquia possa ser melhor visualizada, apresenta-se a Figura 1, considerando o contexto de uma biblioteca:

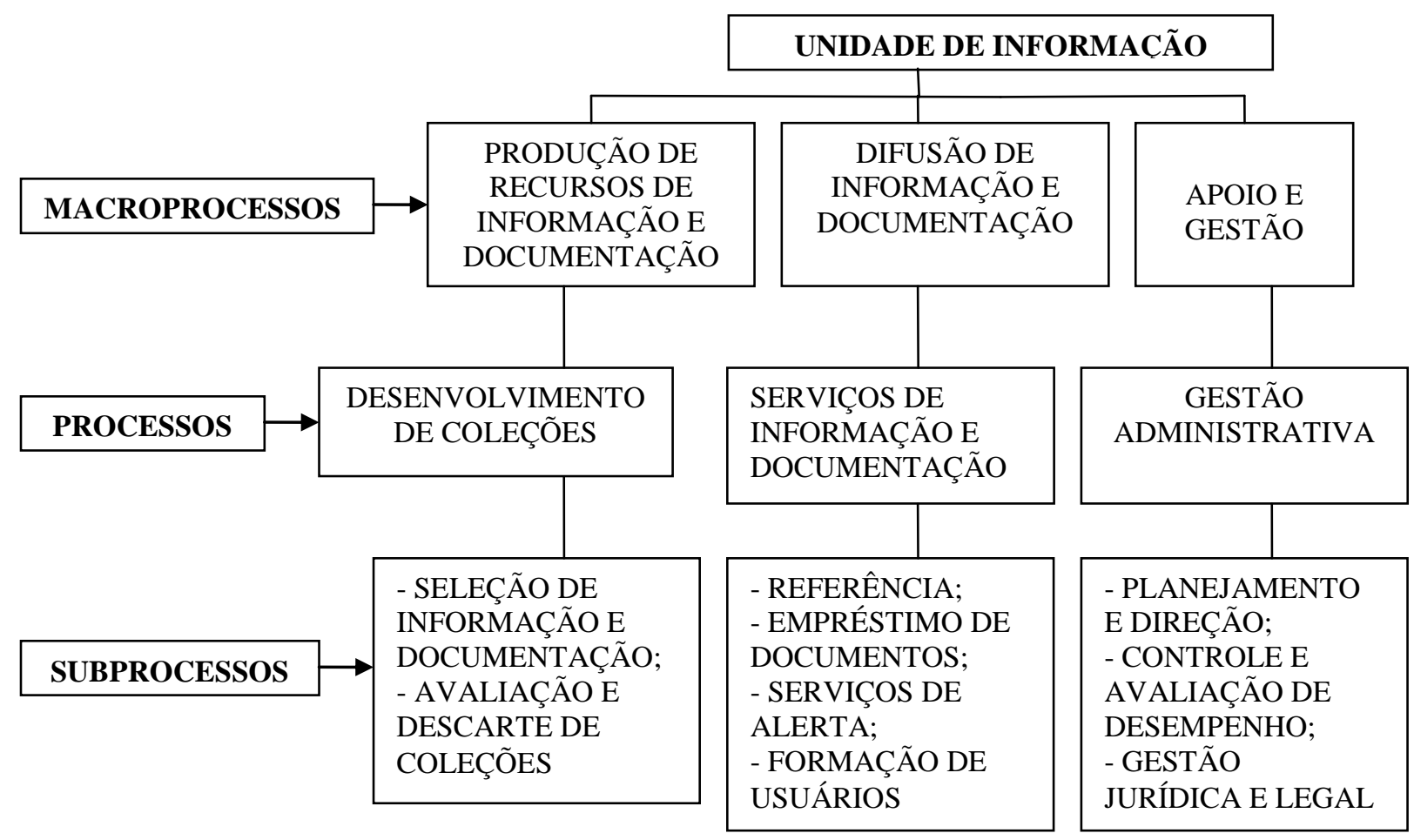

FIGURA 1 - Macroprocessos, processos e subprocessos em unidades de informação.

Fonte: Adaptado de Molina Molina et al., 2004.

O nível de abrangência a ser considerado pela instituição vai depender do tipo de análise que se pretende fazer. No entanto, se o objetivo for a implantação da Gestão por Processos, julga-se que quanto mais aprofundada for a análise melhor, pois, acredita-se que, se houver falhas a serem detectadas, as mesmas estarão no nível dos subprocessos, atividades e tarefas. Cada um desses níveis pode ser aprofundado ainda mais através da utilização de ferramentas como, por exemplo, os fluxogramas.

Além da análise dos processos em si, o Mapeamento de Processos também proporciona que sejam identificadas as pessoas envolvidas em cada uma das etapas do fluxo, fazendo com que as atribuições de responsabilidades sejam feitas de forma clara. Outra possibilidade trazida pelo Mapeamento é a identificação das interfaces dos processos da instituição com os processos de sua mantenedora. No caso dos processos de um setor de 
aquisições de uma biblioteca universitária, por exemplo, podem-se identificar relações com os setores financeiros ou de patrimônio da universidade.

Outras vantagens que podem ser alcançadas com o Mapeamento de Processos, além das já mencionadas, são: documentação e padronização dos processos; integração dos processos, possibilitando a simplificação das rotinas; redução de custos, através da eliminação de retrabalhos e de atividades que não agregam valor ao resultado final. De acordo com Mello et al. (2002), “o principal benefício obtido pelo mapeamento [...] é o surgimento de uma visão e do entendimento de um processo compartilhado por todos os envolvidos" (apud BARBEDO; RIBEIRO; MARCELINO, [2009], p. 3). Ou seja, quanto mais os processos forem entendidos, mais as pessoas entenderão que não estão isoladas e que compartilham de um todo maior, que trabalha em prol de um único objetivo.

Assim, o Mapeamento de Processos só vem trazer benefícios para a instituição que a implementar, uma vez que, seu principal objetivo é “[...] buscar um melhor entendimento dos processos de negócios existentes e dos futuros para melhorar o nível de satisfação do cliente e aumentar [o] desempenho do negócio" (CAMPOS; LIMA, 2012, p. 7, grifo nosso). Mais uma vez é destacada a importância da satisfação do cliente, preocupação principal da Gestão da Qualidade.

\subsection{Gestão da qualidade, gestão por processos e mapeamento de processos em bibliotecas}

Com os avanços tecnológicos e grande aumento da quantidade de informações existentes, as bibliotecas começam a ter que se adequar a essa dinâmica. Isso inclui a preocupação com a qualidade dos serviços oferecidos, que faz com que os profissionais passem a ter que conhecer as metodologias existentes para a garantia dessa qualidade, adequando-as a seu ambiente de trabalho. No entanto, a preocupação dos profissionais bibliotecários com a qualidade dos serviços oferecidos não é novidade na área. De acordo com Vergueiro, “[...] fornecer a informação correta e no momento certo ao usuário foi sempre parte dos dogmas da profissão" (2002, p. 9). Segundo o autor, as 5 leis de Ranganathan ${ }^{4}$ já evidenciavam isso, o que denota que a Gestão da Qualidade pode sim ser aplicada em bibliotecas ou serviços de informação, pois, na mencionada lei:

\footnotetext{
${ }^{4} 1$ - Os livros são para usar; 2 - A cada leitor seu livro; 3 - A cada livro seu leitor; 4 - Poupe o tempo do leitor; 5 - A biblioteca é um organismo em crescimento. (RANGANATHAN, 2009, p. xi). 
[...] estão o produto com o qual os profissionais da informação trabalham, a consciência sobre a importância do cliente e da satisfação de suas necessidades de maneira eficiente, a percepção da necessidade de se definir processos de trabalho que poupem o tempo desse cliente [...] e o entendimento de que as instituições de informação constituem organismos dinâmicos, em crescimento. Assim, concluo que, a priori, nada existe que impeça a aplicação da gestão da qualidade no ambiente da informação (VERGUEIRO, 2002, p. 9-10).

As teorias da Gestão da Qualidade, que antes eram aplicadas em empresas industriais, podem ser aplicadas em ambientes que oferecem serviços também, pois, assim como "as empresas são grandes coleções de processos" (GONÇALVES, 2000, p. 6), as bibliotecas também o são (como foi demonstrado na Figura 1). Além disso, assim como o oferecimento de um produto de qualidade vai interferir na imagem que o cliente tem da empresa, o oferecimento de um serviço também influenciará na percepção dessa imagem, pois, pode ser entendido como "[...] um ato ou desempenho que cria benefícios para clientes por meio de uma mudança desejada no - ou em nome do - destinatário do serviço" (LOVELOCK; WRIGHT, 2001, p. 5).

Nesse contexto, a melhoria da qualidade dos serviços também está diretamente relacionada ao profundo entendimento dos processos realizados para que os mesmos sejam oferecidos. Dessa forma, se faz necessária a aplicação de técnicas gerenciais adequadas como as já mencionadas Gestão por Processos e Mapeamento de Processos. Dessa forma, o bibliotecário, de organizador de acervos, passa a ser um gestor de processos e serviços, visando à elevação dos níveis de satisfação dos usuários.

\section{Metodologias PARA o MAPEAMENTo de PROCESSOS}

No levantamento bibliográfico realizado foram encontradas cinco metodologias para o Mapeamento de Processos, todas com aplicações práticas em bibliotecas. Nesse sentido, serão apresentados os seguintes modelos: Modelagem de Processos de Negócios (MPN), aplicado no Sistema Integrado de Bibliotecas da Universidade de São Paulo (SIBi/USP); Metodologia ARIS (Architecture of Integrated Information Systems), aplicado na Biblioteca Comunitária da Universidade Federal de São Carlos (UFSCar); Formulário SIPOC, aplicado na Rede de

Bibliotecas do Serviço Nacional de Aprendizagem Comercial de Santa Catarina (SENAC/SC); Servpro, aplicado na Biblioteca Universitária Central da Universidade Federal 
de Santa Catarina (BU/UFSC) e Roteiro do INPE, aplicado no Serviço de Informação e Documentação (SID) do Instituto Nacional de Pesquisas Espaciais (INPE).

\subsection{Modelagem de Processos de Negócios (MPN)}

A Modelagem de Processos de Negócios (MPN) foi utilizada por Di Francisco (et al., 2010) para mapear os processos das bibliotecas do Sistema Integrado de Bibliotecas da Universidade de São Paulo (SIBi/USP) e, dessa forma, conseguir identificar, registrar e padronizar os serviços. Através da utilização deste método, foi possível identificar e descrever graficamente todos os processos essenciais, gerenciais e de apoio existentes no Sistema de Bibliotecas, além de novos indicadores de desempenho. A MPN trata-se de um submodelo da metodologia Enterpreise Knowledge Development (EKD), que abrange um conjunto de técnicas de detalhamento da execução das atividades, das diretrizes para a realização dos trabalhos e dos fluxos de informação entre os processos por meio de uma representação gráfica de fácil assimilação. O submodelo é “[...] usado para definir processos organizacionais, e a forma pela qual eles interagem e manuseiam a informação e os materiais" (PÁDUA, 2004, p. 37).

No caso do SIBi/USP, a partir do estabelecimento dos macroprocessos foi possível identificar processos, subprocessos, atividades, instruções de trabalho, fluxos e indicadores. Dentre os macroprocessos foram identificados 2 essenciais (como, por exemplo, "Acesso contínuo à informação e ao documento"), 5 gerenciais (como, por exemplo, "Gestão de pessoas) e 4 de apoio (como, por exemplo, “Apoio às revistas científicas da USP”), que reúnem 115 atividades. Cada um desses macroprocessos foi detalhado em planilha ${ }^{5}$.

Com relação aos indicadores, foram adotados como parâmetro os quatro definidos pelo Projeto SIBindica ${ }^{6}$ (GRANDI et al., 2008). Os quatro indicadores, que foram validados através de aplicação de piloto em bibliotecas do SIBi/USP, são: Uso da coleção de livros e outros materiais não periódicos; Rapidez do processamento técnico; Disponibilidade do documento; Agilidade no EEB e Comutação Bibliográfica. Além desses, foi identificada a necessidade do estabelecimento de mais dois: Agilidade na aquisição e Satisfação do Usuário (PAQ). Além da elaboração de planilhas para a descrição dos macroprocessos, também foi definido um modelo de registro para os indicadores de desempenho ${ }^{7}$.

\footnotetext{
${ }^{5}$ Para verificar exemplos dessas planilhas, consulte o trabalho de Di Francisco et al. (2010).

${ }^{6}$ Estudo de indicadores de desempenho sistêmico, com base em padrões nacionais e internacionais.

${ }^{7}$ Para verificar exemplos desses modelos de registro, consulte o trabalho de Di Francisco et al. (2010).

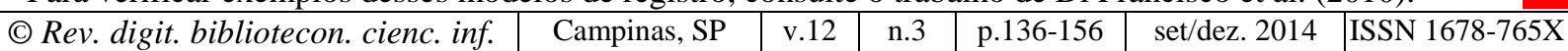


O trabalho com a descrição dos mapeamentos dos processos do $\mathrm{SIBi} / \mathrm{USP}$ não apresenta como foram representados os fluxos de cada um deles. Apenas é citado que estão sendo elaborados em forma de "modelos de referência" que, de acordo com Guerrini et al. $(2009$, p. 7) "[...] são uma representação de um conjunto de elementos organizados entre si para uma finalidade. [...] sua função é facilitar a compreensão do papel dos envolvidos no processo para permitir eventuais melhorias."

No caso do SIBi/USP, a elaboração dos "modelos de referência" para os seus processos é apresentada no trabalho de Coletta et al. (2010). Tal elaboração foi realizada a partir dos macroprocessos identificados no trabalho anterior ${ }^{8}$. A seguir, na Figura 2, pode ser verificado o modelo de referência para o processo "Avaliação de satisfação do usuário":

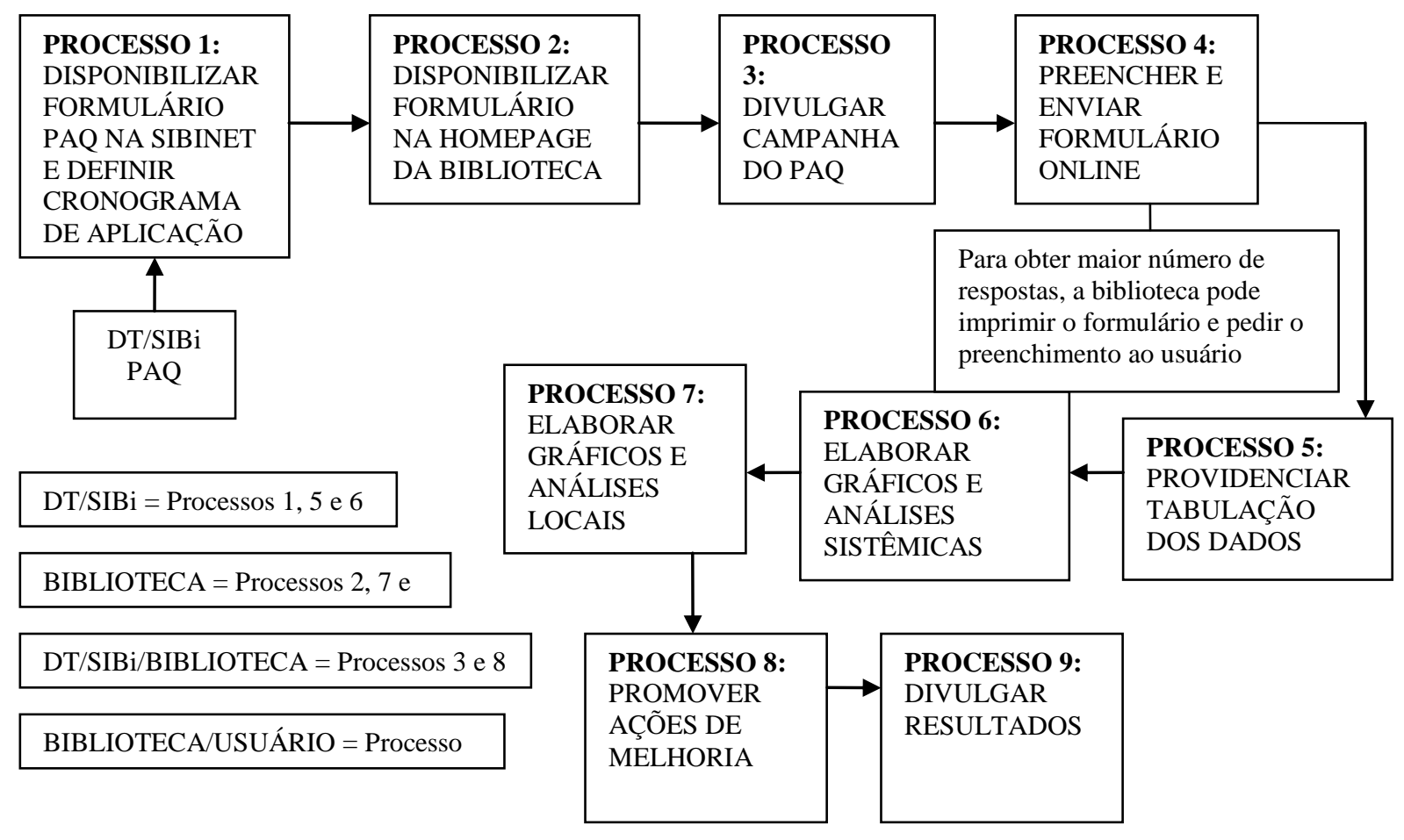

O PAQ - Programa de Avaliação das bibliotecas do SIBi/USP é um processo do SIBi aplicado a cada dois anos com a assessoria de um grupo de estudos responsável pela sua definição e implementação.

FIGURA 2 - Modelo de referência do processo "Avaliação de satisfação do usuário" Fonte: Adaptado de COLETTA et al., 2010, p. 6.

Segundo Coletta et al. (2010) o EKD, bem como seu submodelo MPN, é bastante utilizado na área de Engenharia de Produção. No entanto, como pode ser visto, ele pode

\footnotetext{
${ }^{8}$ Di Francisco (2010).
} 
perfeitamente atender ao trabalho de Mapeamento de Processos no contexto de uma biblioteca.

\subsubsection{ARIS/EPC}

Além da elaboração de planilhas e dos "modelos de referência", para que uma MPN possa ser colocada em prática existe, também, a metodologia ARIS (Architecture of Integrated Information Systems). Tal metodologia “[...] está fundamentada na utilização de uma grande variedade de modelos e objetos através dos quais os processos de negócio de uma organização podem ser representados e analisados [...]." (GONÇALVES, 2010, p. 29). Dentre os modelos existentes na metodologia ARIS, está o EPC, utilizado pela autora supracitada para mapear os processos do serviço de atendimento ao usuário da Biblioteca Comunitária da Universidade Federal de São Carlos (UFSCar).

EPC (Event Driven Process Chain - Cadeia de Processos Dirigida por Eventos) é parte simplificada da metodologia ARIS, onde um processo é modelado segundo o fluxo de eventos e funções presentes nos processos. Seus principais componentes são:

$\checkmark$ Funções: são as atividades, as tarefas ou os passos que precisam ser executados num processo;

$\checkmark$ Eventos: situações que ocorrem antes ou depois da execução de uma função;

$\checkmark$ Conectores lógicos: unificam e separam os fluxos segundo os conectores E, OU ou OU-exclusivo;

$\checkmark$ Caminho: indica que aquele passo é descrito por meio de outro diagrama completo (EPC).

No trabalho de Mapeamento dos Processos da Biblioteca Comunitária da UFSCAR, após a identificação dos macroprocessos, os processos existentes foram detalhados através de $\mathrm{EPCs}^{9}$.

\subsection{Formulário SIPOC}

A metodologia do Formulário SIPOC foi utilizada por Coelho (2011) para mapear os processos das 20 Bibliotecas da Rede do Serviço Nacional de Aprendizagem Comercial de Santa Catarina (SENAC/SC). A abreviação SIPOC significa Supply, Inputs, Process, Output e Consumers. Dessa forma, a metodologia permite identificar as entradas, os fornecedores, as

${ }^{9}$ Para verificar exemplos de EPCs, consulte o trabalho de Gonçalves (2010).

\begin{tabular}{l|l|l|l|l|l|l} 
(C) Rev. digit. bibliotecon. cienc. inf. & Campinas, SP & v.12 & n.3 & p.136-156 & set/dez. 2014 & ISSN 1678-765X \\
\hline
\end{tabular} 
atividades, as saídas e os clientes presentes em cada processo. Além disso, “[...] é um meio efetivo de comunicação entre os membros da equipe, que facilita a visualização para membros que ainda não conhecem o processo e precisam de uma visão mais sistêmica antes de se aprofundarem nos detalhes." (FINAMORE JR., 2008, p. 41).

No caso da Rede de Bibliotecas do SENAC/SC, as atividades desenvolvidas para o Mapeamento dos Processos foram:

[...] a) Identificar os processos essenciais de cada área e a forma como estão sendo executados; bem como seus objetivos; b) Identificar as atividades que compreendem o processo, sua sequência lógica e os pontos de decisão, bem como as unidades organizacionais envolvidas e as relações de dependência entre as etapas do processo; c) Levantar os documentos e sua regulamentação; d) Identificar oportunidades de melhoria e apresentar uma proposta de mudança (COELHO, 2011, p. 4).

Dessa forma, foram identificados oito processos gerais e elaborados fluxogramas para cada um deles, sendo possível otimizar e padronizar suas respectivas atividades.

\subsection{Servpro}

A técnica denominada Servpro ${ }^{10}$ foi utilizada por Santos, Fachin e Varvakis (2003) para o Mapeamento dos Processos da Biblioteca Universitária Central da Universidade Federal de Santa Catarina (BU/UFSC). Baseado no IDEF3 (Integrated DEFinition - técnica de gestão de processos industriais desenvolvida pela Força Aérea dos Estados Unidos), o Servpro foi adaptado para mapear os processos de serviços levando em conta o ponto de vista do usuário. Dessa forma,

É importante destacar que o Servpro abrange somente os processos de que o usuário participa (processos de linha de frente), pois considera que a melhoria da qualidade em serviços ocorre a partir das atividades que são percebidas pelo usuário. Assim, as interações usuário/organização que ocorrem durante o processo são mapeadas na forma que o usuário as vivencia. (SANTOS; FACHIN; VARVAKIS, 2003, p. 87).

O Servpro abrange dois elementos - diagrama e documento de elaboração ${ }^{11}$ :

$\checkmark$ Diagrama: representa o processo graficamente, decompondo-o de forma hierárquica até o nível de detalhamento desejado (subprocesso). Seus elementos básicos são: as

\footnotetext{
${ }^{10}$ Junção das palavras "serviço" e "processo".

${ }^{11}$ Para verificar exemplos de diagramas e de documentos de elaboração, consulte o trabalho de Santos; Fachin; Varvakis (2003).

\begin{tabular}{l|l|l|l|l|l|l}
\hline (C) Rev. digit. bibliotecon. cienc. inf. & Campinas, SP & v.12 & n.3 & p.136-156 & set/dez. 2014 & ISSN 1678-765X \\
\hline
\end{tabular}
}


atividades de interação (as atividades de cada um dos processos, onde há interação com o usuário); as setas (que conectam as atividades de interação); as junções (indicam as ramificações do processo, através das atividades que ocorrem paralela ou alternativamente) e go-to (utilizado quando há necessidade de indicar uma ligação com a próxima ocorrência no processo e isso não tiver sido feito por uma seta).

$\checkmark$ Documento de elaboração: complementa a representação do processo presente no diagrama, fornecendo informações adicionais sobre as atividades. É utilizado nas atividades de interação presentes no mais baixo nível hierárquico do diagrama e, portanto, não serão mais decompostas, o que justifica a necessidade da apresentação de maiores detalhes sobre elas. Tais informações auxiliam na avaliação de desempenho do processo. Seus elementos básicos são: nome, número e rótulo da atividade de interação (identificam a atividade e seu nível hierárquico); elementos de contato (representam os recursos com os quais o usuário tem contato e, por isso, podem afetar a qualidade que percebe do serviço); interações entre os elementos e o usuário (subatividades que não foram representadas graficamente e que correspondem às relações de troca entre o usuário e a prestação do serviço); operações dos elementos (operações necessárias para o fornecimento do serviço); operações do usuário (operações que o usuário desempenha); determinantes da qualidade (parâmetros utilizados pelo usuário para avaliar a qualidade do serviço) e medidas de desempenho (indica o nível de desempenho das operações realizadas).

O Servpro tem sua gênese em uma técnica de gestão de processos industriais (IDEF3). No entanto, foi perfeitamente adaptado para a gestão de processos de serviços sob a ótica do usuário, podendo, dessa forma, ser utilizado para o Mapeamento de Processos em bibliotecas.

\subsection{Roteiro do INPE}

O Serviço de Informação e Documentação (SID) do Instituto Nacional de Pesquisas Espaciais (INPE), baseado numa revisão de literatura, elaborou um roteiro próprio para o mapeamento de seus processos. Tal roteiro, apresentado por Barbedo, Ribeiro e Marcelino ([2009]) é formado pelas seguintes etapas:

1 - Formação da equipe: constituição e capacitação da equipe que participará do mapeamento dos processos; 
2 - Elaboração do plano de trabalho: realização de reuniões para estabelecer os objetivos e metas a serem cumpridas, as atividades a serem desenvolvidas, os recursos necessários, resultados, prazos de entrega, apresentação do projeto à Direção, prever análises periódicas e implementação de melhorias;

3 - Diagnóstico do SID: identificação da estrutura organizacional e mapeamento do quadro de pessoal do SID;

4 - Entrevistas com a equipe do SID: interação da equipe com o projeto de mapeamento e preenchimento de planilha descrevendo as tarefas realizadas;

5 - Elaboração dos fluxos: elaboração dos fluxos das tarefas identificadas na etapa 4;

6 - Análise e validação dos fluxos com as equipes: após a elaboração dos fluxos, os mesmos são validados a partir do preenchimento de quadros resumos e apresentação de soluções para os problemas identificados ${ }^{12}$;

7 - Definição dos processos: com base na validação dos fluxos, definem-se os processos da unidade (agrupamento dos subprocessos) e, depois, os macroprocessos (agrupamento dos processos). Nessa etapa, é possível identificar os relacionamentos entre os subprocessos e os processos;

8 - Identificação de indicadores: após a definição dos processos e macroprocessos, identifica-se indicadores para avaliar seus desempenhos e colocar medidas corretivas em prática.

$\mathrm{Na}$ época em que o trabalho foi escrito, as etapas 7 e 8 ainda não tinham sido colocadas em prática. Além disso, também se pretendia elaborar manuais de trabalho, descrevendo as tarefas de cada membro do SID.

Como é possível perceber, os modelos para o Mapeamento de Processos encontrados na literatura são perfeitamente aplicáveis em bibliotecas. No entanto, cada um traz uma especificidade diferente.

A MPN é uma metodologia bem completa que descreve não apenas os processos, mas, também, seus indicadores de desempenho, o que é de suma importância para a avaliação dos processos desenvolvidos. Os fluxos de trabalho são apresentados por meio de planilhas e dos chamados "modelos de referência" que, no caso do SIBi/USP mostram não apenas os fluxos de trabalho internos ao SIBi, mas, também, as suas interações com outras áreas ou atores envolvidos no processo. Os EPCs, parte simplificada da metodologia ARIS, são espécies de

12 Para verificar exemplos de quadros resumos e apresentação de soluções para os problemas identificados, consulte o trabalho de Barbedo; Ribeiro; Marcelino ([2009]).

\begin{tabular}{l|l|l|l|l|l|l} 
(C) Rev. digit. bibliotecon. cienc. inf. & Campinas, SP & v.12 & n.3 & p.136-156 & set/dez. 2014 & ISSN 1678-765X \\
\hline
\end{tabular}


fluxogramas que não possuem nenhum outro documento de apoio, o que traz a impressão de metodologia incompleta, se comparada às demais encontradas.

O Formulário SIPOC também é uma metodologia bem completa e parece fácil de ser colocada em prática. Além do formulário em si, que traz toda a descrição dos fornecedores, das entradas, das atividades, das saídas e dos clientes de cada um dos processos e, portanto, pode fazer parte de um manual de procedimentos, possui, também, a descrição gráfica dos processos em fluxogramas tradicionais. Seus "mapas de relacionamento" são bem interessantes, uma vez que, mostram, claramente, que o cliente de um subprocesso é fornecedor do próximo, demonstrando a cadeia de relacionamentos existente entre eles.

O Servpro parece ser uma metodologia complexa de ser aplicada. Além de um mesmo processo ser representado através da elaboração de vários diagramas, e não através de um único fluxograma, sua aplicação leva em conta o ponto de vista do usuário com relação às atividades desenvolvidas. Dessa forma, sua aplicação seria mais viável em setores em que há participação direta dos usuários.

O Roteiro do INPE, por sua vez, não é explicitado por completo na literatura encontrada, faltando a apresentação das etapas 7 e 8 . No entanto, a descrição da etapa 7 sugere que a metodologia segue o caminho inverso dos outros modelos, fazendo a descrição dos procedimentos dos subprocessos até chegar nos macroprocessos. Julga-se estranho esse tipo de aplicação, pois parece ser importante primeiramente ter a visão do todo, para depois partir para as situações específicas.

Dentre os pontos comuns encontrados na aplicação das metodologias encontradas estão: entrevistas com os atores envolvidos nos processos; representações gráficas dos procedimentos; identificação de macroprocessos, processos e subprocessos, além da análise de documentos internos já existentes.

A fim de se condensar as características apresentadas é realizada, no Quadro 1, comparação dos principais aspectos de cada uma das metodologias:

QUADRO 1 - Comparativo das metodologias apresentadas para o Mapeamento de Processos 


\begin{tabular}{|c|c|c|c|}
\hline $\begin{array}{l}\text { METODOL } \\
\text { OGIA }\end{array}$ & DESCRIÇÃO & PONTOS POSITIVOS & $\begin{array}{c}\text { PONTOS } \\
\text { NEGATIVOS }\end{array}$ \\
\hline MPN & $\begin{array}{l}\text { Conjunto de técnicas de } \\
\text { detalhamento da execução } \\
\text { das atividades, das } \\
\text { diretrizes para a realização } \\
\text { dos trabalhos e dos fluxos } \\
\text { de informação entre os } \\
\text { processos por meio de uma } \\
\text { representação gráfica de } \\
\text { fácil assimilação. }\end{array}$ & $\begin{array}{l}\text { Identificação dos processos, subprocessos, } \\
\text { atividades, instruções de trabalho, fluxos e } \\
\text { indicadores; elaboração de planilhas para a } \\
\text { descrição dos macroprocessos; apresenta modelo de } \\
\text { registro para os indicadores de desempenho; } \\
\text { apresentação dos fluxos em forma de "modelos de } \\
\text { referência"; não mostra apenas os fluxos de trabalho } \\
\text { internos, mas, também, as interações com outras } \\
\text { áreas ou atores envolvidos no processo. }\end{array}$ & \\
\hline EPC & $\begin{array}{l}\text { O processo é modelado } \\
\text { segundo o fluxo de eventos } \\
\text { e funções presentes nos } \\
\text { processos. }\end{array}$ & $\begin{array}{l}\text { Apresentação dos processos através de fluxogramas } \\
\text { (cadeias de processos). }\end{array}$ & $\begin{array}{l}\text { Fluxogramas não } \\
\text { possuem nenhum outro } \\
\text { documento de apoio. }\end{array}$ \\
\hline $\begin{array}{l}\text { FORMULÁR } \\
\text { IO SIPOC }\end{array}$ & $\begin{array}{l}\text { Permite identificar as } \\
\text { entradas, os fornecedores, } \\
\text { as atividades, as saídas e os } \\
\text { clientes presentes em cada } \\
\text { processo. }\end{array}$ & $\begin{array}{l}\text { Representação dos processos através da utilização } \\
\text { de "mapas de relacionamento" (formulário sipoc } \\
\text { que descreve os fornecedores, as entradas, as } \\
\text { atividades, as saídas e os clientes de cada um dos } \\
\text { processos) que mostram, claramente, que o cliente } \\
\text { de um subprocesso é fornecedor do próximo, } \\
\text { demonstrando a cadeia de relacionamentos existente } \\
\text { entre eles; utilização de fluxogramas tradicionais; } \\
\text { metodologia simples de ser colocada em prática. }\end{array}$ & \\
\hline SERVPRO & $\begin{array}{l}\text { Mapeia os processos de } \\
\text { serviços levando em conta } \\
\text { o ponto de vista do } \\
\text { usuário. }\end{array}$ & $\begin{array}{l}\text { Representa os processos através da elaboração de } \\
\text { diagramas e de documentos de elaboração. }\end{array}$ & $\begin{array}{l}\text { Um mesmo processo é } \\
\text { representado por } \\
\text { vários diagramas, } \\
\text { não através de um } \\
\text { único fluxograma; } \\
\text { abrange somente os } \\
\text { processos de que o } \\
\text { usuário participa } \\
\text { (processos de linha de } \\
\text { frente). }\end{array}$ \\
\hline $\begin{array}{l}\text { ROTEIRO } \\
\text { DO INPE }\end{array}$ & $\begin{array}{l}\text { Composto por oito etapas } \\
\text { elaboradas com base } \\
\text { numa revisão }\end{array}$ & $\begin{array}{l}\text { Prevê a capacitação da equipe que participará do } \\
\text { mapeamento dos processos, bem como o } \\
\text { planejamento das metas e prazos a serem } \\
\text { cumpridos; validação dos fluxos, com o } \\
\text { preenchimento de quadros resumos e } \\
\text { apresentação de soluções para os problemas } \\
\text { identificados; identificação de indicadores para } \\
\text { avaliação do desempenho dos processos. }\end{array}$ & $\begin{array}{l}\text { Não é explicitado por } \\
\text { completo, faltando a } \\
\text { apresentação das } \\
\text { etapas } 7 \text { e 8; segue o } \\
\text { caminho inverso dos } \\
\text { outros modelos, } \\
\text { fazendo a descrição dos } \\
\text { procedimentos e dos } \\
\text { subprocessos } \\
\text { chegar até } \\
\text { macropocessos. nos }\end{array}$ \\
\hline
\end{tabular}

\section{CONSIDERAÇÕES FINAIS}

As instituições que almejam a Gestão da Qualidade dos produtos e serviços que oferecem a seus clientes devem estar abertas para adotar novos procedimentos e rotinas de trabalho que busquem alcançar o atendimento das necessidades e a satisfação daqueles que as procuram. Como foi possível perceber, a Gestão por Processos é uma das abordagens que devem ser consideradas por tais instituições, uma vez que, as atividades e recursos envolvidos 
passam a ser vistos de forma integrada, sempre buscando a qualidade do resultado alcançado no final do processo, ou seja, a qualidade do que é fornecido ao cliente.

Para tanto, é de suma importância que as instituições conheçam seus processos com profundidade e, nesse sentido, é importante que seja colocada em prática a atividade de Mapeamento de Processos. Tal atividade fornece condições para que as instituições consigam analisar os fluxos de trabalho identificando as atividades desenvolvidas em cada um dos processos, diagnosticando possíveis deficiências e melhorias, bem como os responsáveis envolvidos.

Toda essa dinâmica surgiu, inicialmente, em empresas industriais. No entanto, ficou claro, a partir das metodologias apresentadas, que as instituições que oferecem serviços, especialmente as bibliotecas e serviços de informação, também podem se valer das vantagens que o Mapeamento de Processos pode trazer. Essas vantagens como, por exemplo, a documentação, padronização e integração dos processos, são imprescindíveis na rotina de trabalho de qualquer setor, uma vez que, a padronização dos processos do dia-a-dia possibilita, ao profissional, gastar seu tempo com atividades que demandem mais raciocínio, em detrimento de atividades rotineiras que, se bem documentadas, podem ser colocadas em prática por um assistente. A documentação dos processos também traz vantagens, pois, possibilita que os novos funcionários tenham manuais que os auxiliem na realização das atividades.

Acredita-se que, assim como foi demonstrado, as metodologias encontradas na literatura podem perfeitamente ser aplicadas e, até mesmo, adaptadas à realidade de cada instituição, chegando-se em metodologias próprias e de fácil aplicação para o mapeamento dos processos e, conseqüentemente, para o aprimoramento das atividades desenvolvidas como, por exemplo: identificação das pessoas envolvidas em cada uma das atividades, fazendo com que as atribuições de responsabilidades sejam feitas de forma clara; identificação das interfaces dos processos internos com os processos da mantenedora da biblioteca; simplificação das rotinas e redução de custos, através da eliminação de retrabalhos e de atividades que não agregam valor ao resultado final.

\section{REFERÊNCIAS}


ABREU, M. C.; ANDALIA, R. C. Gerencia total de la calidad en las organizaciones.

ACIMED, Habana, v. 6, n. 2, p. 79-92. 1998. Disponível em:

<http://www.bvs.sld.cu/revistas/aci/vol6_2_98/aci02298.pdf>. Acesso em: 07 abr. 2013.

ASSOCIAÇÃO BRASILEIRA DE NORMAS TÉCNICAS. Sistemas de gestão da qualidade - fundamentos e vocabulário: NBR ISO 9000. Rio de Janeiro: ABNT, 2000. 29 p. Disponível em:

<http://www.ct.ufpb.br/pesquisas/gesp/Gestao\%20da\%20Qualidade/ISO9000.pdf >. Acesso em: 10 fev. 2013.

BARBEDO, Simone Angélica Del-Ducca; RIBEIRO, Marciana Leite; MARCELINO, Silvia Castro. Mapeamento dos processos no serviço de informação e documentação do INPE. [2009]. 12 p. Disponível em:

<http://www.academia.edu/869065/Mapeamento_dos_processos_no_Servico_de_Informacao _e_Documentacao_do_INPE>. Acesso em: 12 fev. 2013.

CAMPOS, Renata Alves; LIMA, Sandra Maria Peron de. Mapeamento de processos: importância para as organizações. Rio de Janeiro: UFRRJ, 2012. 33 slides. Disponível em: <http://www.ufrrj.br/codep/materialcursos/projetomapeamento/MapeamentoProcessos.pdf $>$. Acesso em: 12 fev. 2013.

COELHO, Juliane Patrício. O mapeamento dos processos operacionais na rede de bibliotecas SENAC/RS. In: CONGRESSO BRASILEIRO DE BIBLIOTECONOMIA, DOCUMENTAÇÃO E CIÊNCIA DA INFORMAÇÃO, 24., 2011, Maceió. Anais... Maceió: FEBAB, 2011.

COLETTA, Teresinha das Graças et al. Modelos de referência para bibliotecas: a experiência do SIBi/USP. In: SEMINÁRIO NACIONAL DE BIBLIOTECAS UNIVERSITÁRIAS, 16., 2010, Rio de Janeiro. Anais... Rio de Janeiro: UFRJ, 2010. Disponível em:

<http://www.gapcongressos.com.br/eventos/z0070/trabalhos/final_023.pdf>. Acesso em: 02 mar. 2013.

DI FRANCISCO, Maria Helena et al. Serviços e produtos do SIBi/USP: descrição dos processos essenciais, gerenciais e de apoio. In: SEMINÁRIO NACIONAL DE BIBLIOTECAS UNIVERSITÁRIAS, 16., 2010, Rio de Janeiro. Anais... Rio de Janeiro: UFRJ, 2010. Disponível em:

<http://www.gapcongressos.com.br/eventos/z0070/trabalhos/final_200.pdf>. Acesso em: 02 mar. 2013.

FINAMORE JR., Weyder Alves. Aplicação do modelo six sigma na administração de operações: estudo de caso no tempo de entrada de materiais importados. 2008. Trabalho de Conclusão de Curso - Universidade Federal de Juiz de Fora. Juiz de Fora, 2008. Disponível em: 〈http://www.ufjf.br/ep/files/2010/05/TCC-Finamore.pdf>. Acesso em 03 mar. 2013.

GONÇALVES, José Ernesto Lima. As empresas são grandes coleções de processos. Revista de Administração de Empresas - RAE, São Paulo, v. 40, n. 1, p. 6-19, jan./mar. 2000. Disponível em: <http://www.scielo.br/pdf/rae/v40n1/v40n1a02.pdf>. Acesso em: 10 fev. 2013. 
GONÇALVES, Vânia Helena. Modelagem de processos de negócios: aplicação no serviço de atendimento ao usuário da Biblioteca Comunitária da UFSCar. 2010. Trabalho de Conclusão de Curso (Especialização) - Universidade Federal de São Carlos. São Carlos, 2010. Disponível em: <http://www.srh.ufscar.br/blog/cqa/wp-content/uploads/MonografiaV\%C3\%A2nia-Helena-Gon\%C3\%A7alves.pdf>. Acesso em: 08 mar. 2013.

GRANDI, M.E.G. et al. Indicadores de desempenho para bibliotecas universitárias: projeto desenvolvido no SIBi/USP. In: SEMINÁRIO NACIONAL DE BIBLIOTECAS UNIVERSITÁRIAS, 15., 2008, São Paulo. Anais... São Paulo: CRUESP Bibliotecas, 2008. Disponível em: <http://www.sbu.unicamp.br/snbu2008/anais/site/pdfs/3081.pdf>. Acesso em: 07 abr. 2013.

GUERRINI, Fábio Müller. Modelos de referência de gestão da EESC-USP. São Carlos: Cubo, 2009. 46 p. Disponível em:

<http://143.107.182.106/portal/images/stories/docs/ModelosdeReferenciadeGestaodaEESC_ USP.pdf>. Acesso em: 07 abr. 2013.

HAMMER, Michael; CHAMPY, James. Reengineering the corporation: a manifesto for business revolution. New York: HarperCollins Publishers, 1993. 233 p.

LOVELOCK, Christopher; WRIGHT, Lawren. Serviços: marketing e gestão. São Paulo: Saraiva, 2001. 416 p.

MARANHÃO, Mauriti; MACIEIRA, Maria Elisa Bastos. O processo nosso de cada dia: modelagem de processos de trabalho. Rio de Janeiro: Qualitymark Editora, 2004. 250 p.

MARCO, Sueli Aparecida de. Inteligência competitiva: definições e contextualização. Transinformação, Campinas, v. 11, n. 2, p. 95-102, maio/ago. 1999. Disponível em: <http://www.inmetro.gov.br/infotec/artigos/docs/69.pdf>. Acesso em: 10 fev. 2013.

MOLINA MOLINA, Martha Silvia et al. Investigación procesos y costos en las unidades de información. Medellín: Universidad de Antioquia, 2004. Disponível em:

<http://docencia.udea.edu.co/bibliotecologia/procesosycostos/index.html>. Acesso em: 12 fev. 2013.

PÁDUA, Silvia Inês Dallavalle de. Método de avaliação do modelo de processos de negócio do EKD. 2004. 252p. Dissertação (Mestrado) - Escola de Engenharia de São Carlos, Universidade de São Paulo, São Carlos, 2004. Disponível em: <http://www.teses.usp.br/teses/disponiveis/18/18135/tde-25112008-153952/pt-br.php>.

Acesso em: 07 abr. 2013.

RANGANATHAN, Shiyali Ramamrita. As cinco leis da biblioteconomia. Brasília: Briquet de Lemos, 2009. 336 p.

REIS, Margarida Maria de Oliveira; BLATTMANN, Ursula. Gestão de processos em bibliotecas. Revista Digital de Biblioteconomia e Ciência da Informação, Campinas, v. 1, n. 2, p. 1-17, jan./jun. 2004. Disponível em: 
<http://www.sbu.unicamp.br/seer/ojs/index.php/rbci/article/view/292/171>. Acesso em: 10 fev. 2013.

SANTOS, Luciano Costa; FACHIN, Gleisy Regina Bóries; VARVAKIS, Gregorio. Gerenciando processos de serviços em bibliotecas. Ciência da Informação, Brasília, v. 32, n. 2, p. 85-94, maio/ago. 2003. Disponível em: 〈http://www.scielo.br/pdf/ci/v32n2/17037.pdf>. Acesso em: 13 fev. 2013.

VALLS, Valéria Martin. O enfoque por processos da NBR ISO 9001 e sua aplicação nos serviços de informação. Ciência da Informação, Brasília, v. 33, n. 2, p. 172-178, maio/ago. 2004. Disponível em: <http://www.scielo.br/pdf/ci/v33n2/a18v33n2.pdf>. Acesso em: 11 fev. 2013.

VERGUEIRO, Waldomiro de Castro Santos. Qualidade em serviços de informação. São Paulo: Arte \& Ciência, 2002. 124 p.

\section{Como citar este artigo:}

PAULA, Marciléia Aparecida de; VALLS, Valéria Martin; Mapeamento de Processos em Bibliotecas: Revisão de Literatura e Apresentação de Metodologias. Rev. digit. bibliotecon. cienc. inf., Campinas, SP, v.12, n.3, p.136-156, set/dez. 2014. ISSN 1678-765X. Disponível em: <http://www.sbu.unicamp.br/seer/ojs/index.php/rbci>. Acesso em: 31 ago. 2014. 